Procjena stabilnosti uroda zrna i sadržaja ulja hibrida suncokreta AMMI analizom

Stability Estimation of the Grain Yield and Oil Content of Sunflower Hybrids by AMMI analysis

Liović, I., Horvat, D., Mijić, A., Sudarić, A., Duvnjak, T., Markulj Kulundžić, A.

Poljoprivreda/Agriculture

ISSN: $1848-8080$ (Online)

ISSN: 1330-7142 (Print)

https://doi.org/10.18047/poljo.27.1.1

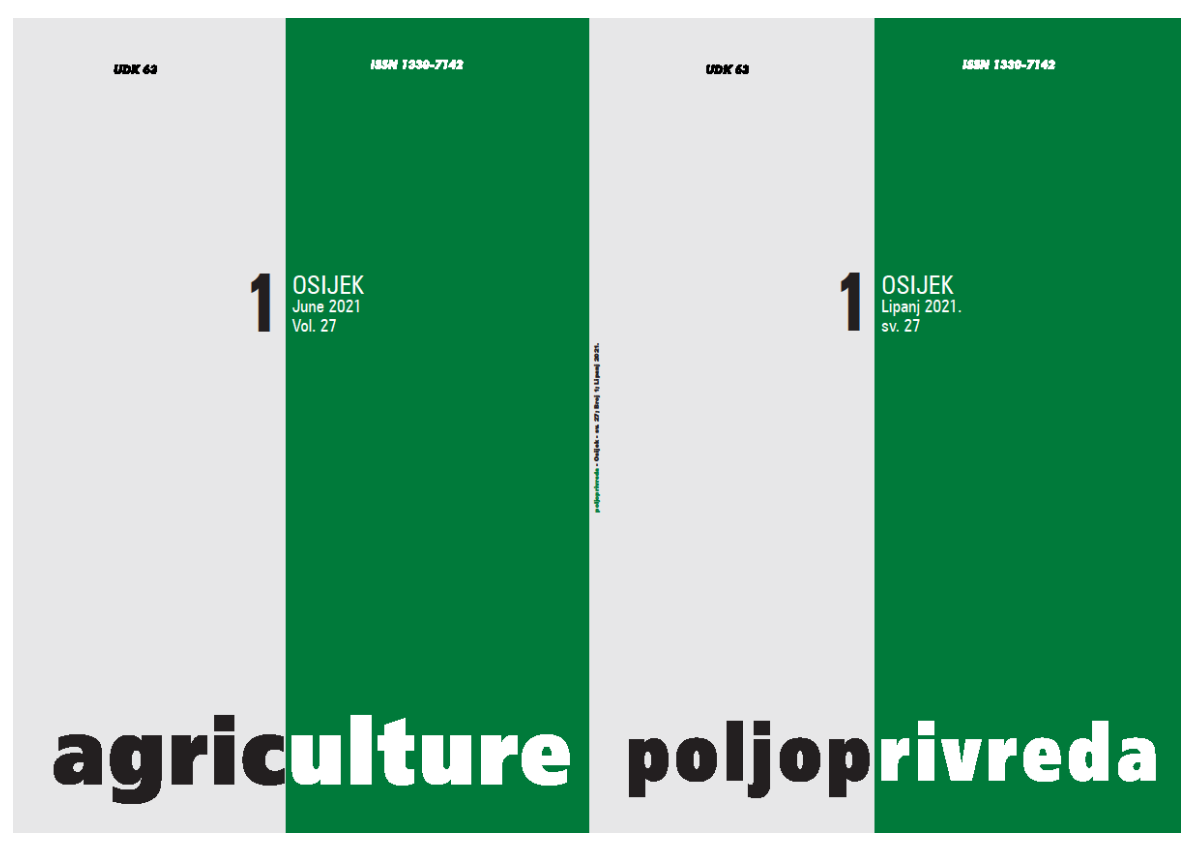

Fakultet agrobiotehničkih znanosti Osijek, Poljoprivredni institut Osijek

Faculty of Agrobiotechnical Sciences Osijek, Agricultural Institute Osijek 


\section{PROCJENA STABILNOSTI URODA ZRNA I SADRŽAJA ULJA HIBRIDA SUNCOKRETA AMMI ANALIZOM}

Liović, I.(1), Horvat, D. ${ }^{(2)}$, Mijić, A. ${ }^{(1)}$, Sudarić, A. ${ }^{(1)}$, Duvnjak, T. $^{(1)}$, Markulj Kulundžić, A. ${ }^{(1)}$

Izvorni znanstveni članak

Original scientific paper

\section{SAŽETAK}

Tijekom triju vegetacijskih sezona (2017.-2019.) postavljeni su poljski pokusi s 18 hibrida suncokreta na površinama Poljoprivrednoga instituta Osijek. Cilj istraživanja je bio procijeniti interakciju genotip x okolina za urod zrna (t/ha) i sadržaj ulja (\%). AMMI analizom (Additive Main Effects and Multiplicative Interaction) procijenjena je interakcija genotip x okolina za oba svojstva. Utvrđene su statistički značajne razlike između genotipova, okolina $i$ interakcija genotip x okolina za urod zrna, pri čemu je relativno najveći udio sume kvadrata imala interakcija genotip $x$ okolina $(41,72 \%)$, a zatim genotip $(20,75 \%)$ i okolina $(2,10 \%)$. Prema visini uroda zrna i stabilnosti, posebno su se istaknuli genotipovi 4, 10, 17 i 11. Od okolina su najveći urod zrna i najmanja interakcija genotip x okolina bili u 2018. godini. Utvrđene su statistički značajne razlike sadržaja ulja između genotipova, okolina $i$ interakcija genotip x okolina, pri čemu je najveći udio sume kvadrata imao genotip $(52,82 \%)$, a zatim okolina $(23,02 \%)$ te interakcija genotip x okolina $(17,27 \%)$. Prema visini sadržaja ulja $i$ stabilnosti posebno su se istaknuli genotipovi $8,13,17,6$ i 16. Od okolina je nešto manji sadržaj ulja imala okolina 2019., ali i znatno manju interakciju genotip x okolina, odnosno znatno veću stabilnost u odnosu na ostale okoline.

Ključne riječi: suncokret, urod zrna, sadržaj ulja, AMMI analiza, interakcija genotip x okolina

\section{UVOD}

Suncokret (Helianthus annuus L.) je najvažnija kultura za proizvodnju kvalitetnoga jestivog ulja u Republici Hrvatskoj. U razdoblju od 2014. do 2018. godine, suncokret se u Hrvatskoj sijao na prosječno 36.779 ha (34.494 do 40.254 ha), s urodom zrna od 2,886 t/ha (FAOSTAT, 2020.). Urod zrna ima najveći utjecaj na urod ulja, što dokazuje statistički visoko značajna pozitivna korelacija između ovih svojstava. Pored toga, urod zrna ima najjači direktan utjecaj na urod ulja i može se koristiti kao selekcijski kriterij za povećanje uroda ulja (Mijić i sur., 2009.).

Na urod zrna i sadržaj ulja jako velik utjecaj imaju okolinski faktori, kao što su tlo i vremenski uvjeti tijekom vegetacije (Galić Subašić i sur., 2017.; Jukić i sur., 2017.; Liović i sur., 2017.; Jug i sur., 2018.). Zbog toga je važno utvrditi reakciju novih hibridnih kombinacija prema okolinskim uvjetima, odnosno utvrditi interakciju genotip x okolina (Gauch, 1996.; Ebdon i Gauch, 2002.; Rao i sur., 2002.).

Za utvrđivanje interakcije genotip $\mathrm{x}$ okolina (GEI) najučinkovitijom se pokazala AMMI analiza (Additive Main Effects and Multiplicative Interaction). Ova analiza kombinira analizu varijance (ANOVA) za glavne učinke genotipa i okoline s glavnim komponentama analize (PCA) interakcije genotip x okolina (Zobel i sur., 1988.; Annicchiarico, 1997.; Gauch, 2006.; Eđed i sur., 2008.; Jocković i sur., 2012., Ćirić i sur., 2017.). Radi bolje preglednosti, rezultati $\mathrm{AMMI}$ analize mogu se prikazati u

(1) Dr. sc. Ivica Liović (ivica.liovic@poljinos.hr), dr. sc. Anto Mijić, dr. sc. Aleksandra Sudarić, dr. sc. Tomislav Duvnjak, dr. sc. Antonela Markulj Kulundžić - Poljoprivredni institut Osijek, Južno predgrađe 17, 31000 Osijek, Hrvatska; (2) Prof. dr. sc. Dražen Horvat - Sveučilište Josipa Jurja Strossmayera u Osijeku, Fakultet agrobiotehničkih znanosti Osijek, Vladimira Preloga 1, 31000 Osijek, Hrvatska 
obliku biplota, koji pokazuju glavne aditivne učinke i interakcije sviju genotipova i okolina (Ebdon i sur., 1998.; Yan i Tinker, 2005.; Li i sur., 2006.).

U Poljoprivrednome institutu Osijek, u okviru oplemenjivačkoga programa suncokreta, svake godine nastaju nove hibridne kombinacije koje se ispituju u poljskim pokusima. Najbolje nove hibridne kombinacije, uz već priznate domaće i strane hibride suncokreta, činile su set odabranih hibrida za istraživanje. Sa svrhom utvrđivanja reakcije 18 hibrida suncokreta prema okolinskim uvjetima proizvodnje i identificiranja hibrida visokoga $\mathrm{i}$ stabilnog uroda zrna i sadržaja ulja, postavljeni su trogodišnji poljski pokusi.

\section{MATERIJAL I METODE}

Istraživanje je provedeno tijekom triju vegetacijskih sezona (2017.-2019.) na površinama Poljoprivrednoga instituta Osijek. Navedene godine istraživanja predstavljale su okoline. U poljskim pokusima bilo je 18 hibrida (genotipova) suncokreta, a od toga 16 hibrida Poljoprivrednoga instituta Osijek: tri priznata $(8,9,18) \mathrm{i}$ 13 novih hibridnih kombinacija $(1,2,5-7,10-17)$ te dva strana hibrida suncokreta (3 i 4) koja se siju na velikim površinama u Republici Hrvatskoj. Pokusi su posijani ručno prema planu slučajnoga bloknog rasporeda u tri ponavljanja. Osnovnu parcelicu su činila četiri reda duljine $4 \mathrm{~m}$, a za obračun su korištena dva unutarnja reda. Razmak između redova bio je $70 \mathrm{~cm}$, a unutar reda 23 $\mathrm{cm}$. Gnojidba i zaštita usjeva od korova, bolesti i štetnika provedeni su prema uobičajenoj proizvodnoj praksi.
Nakon žetve određen je urod zrna, a na uzorcima zrna sadržaj ulja MQA 7005 NMR analizatorom. Na podatcima uroda zrna i sadržaja ulja provedena je dvofaktorska analiza varijance i AMMI analiza varijance korištenjem PROC GLM procedure pomoću statističkoga paketa $S A S$ for Windows 9.1 software, a biploti su načinjeni računalnim programom Microsoft Excel 2016 kao XY dijagram raspršenja (scatter chart).

\section{Vremenske prilike}

Tijekom analiziranoga perioda vremenski su uvjeti bili jako različiti. Srednje mjesečne temperature zraka i mjesečne oborine za razdoblje 2017.-2019. te višegodišnji prosjek (2000.-2019.) za Osijek prikazani su u Tablici 1. Najviše zimskih oborina (I.-III. mjesec) bilo je 2018. $(215,3 \mathrm{~mm})$, zatim 2017. (167,2 mm), a najmanje u 2019. godini $(77,6 \mathrm{~mm})$. Tijekom vegetacije (IV.-IX. mjesec), u odnosu na višegodišnji prosjek, u prosjeku je bilo toplije za $0,3^{\circ} \mathrm{C} 2017$., za $1,3^{\circ} \mathrm{C} 2018$. i za $0,1^{\circ} \mathrm{C}$ 2019. godine. Oborina je bilo manje 2017. za $81,5 \mathrm{~mm}$ i 2018. za $31,3 \mathrm{~mm}$, a 2019. za $145,3 \mathrm{~mm}$ više u odnosu na višegodišnji prosjek.

Analiza oborina po mjesecima pokazala je, u odnosu na višegodišnji prosjek, da je 2017. godine bilo za $101,9 \mathrm{~mm}$ manje oborina u V., VI. i VIII. mjesecu. U 2018., u IV. je i V. mjesecu bilo za 79,4 mm manje oborina, u VI. i VII. mjesecu za 112,4 mm više oborina, a u VIII. i IX. mjesecu ponovo za $64,2 \mathrm{~mm}$ manje oborina. U 2019. je u IV., V. i VI. mjesecu bilo za 120,5 mm, a u VIII. i IX. mjesecu za 29,6 mm više oborina u odnosu na višegodišnji prosjek.

Tablica 1. Srednje mjesečne temperature zraka $\left({ }^{\circ} \mathrm{C}\right)$ i sume mjesečnih oborina $(\mathrm{mm})$ za 0 sijek Table 1. Mean monthly air temperatures $\left({ }^{\circ} \mathrm{C}\right.$ ) and a sum of monthly precipitations ( $\mathrm{mm}$ ) for Osijek

\begin{tabular}{|c|c|c|c|c|c|c|c|c|}
\hline \multirow[b]{2}{*}{$\begin{array}{l}\text { Mjesec } \\
\text { Month }\end{array}$} & \multicolumn{2}{|c|}{2017.} & \multicolumn{2}{|c|}{2018.} & \multicolumn{2}{|c|}{2019.} & \multicolumn{2}{|c|}{$\begin{array}{c}\text { Prosjek - Mean } \\
\text { 2000.-2019. }\end{array}$} \\
\hline & $\begin{array}{l}\text { Temp.* } \\
\text { Temp. }\end{array}$ & $\begin{array}{l}\text { Oborine*** } \\
\text { Precipit. }\end{array}$ & $\begin{array}{l}\text { Temp. } \\
\text { Temp. }\end{array}$ & $\begin{array}{l}\text { Oborine } \\
\text { Precipit. }\end{array}$ & $\begin{array}{l}\text { Temp. } \\
\text { Temp. }\end{array}$ & $\begin{array}{l}\text { Oborine } \\
\text { Precipit. }\end{array}$ & $\begin{array}{l}\text { Temp. } \\
\text { Temp. }\end{array}$ & $\begin{array}{l}\text { Oborine } \\
\text { Precipit. }\end{array}$ \\
\hline I.-III. & 2,9 & 167,2 & 3,2 & 215,3 & 4,6 & 77,6 & 3,5 & 45,9 \\
\hline IV. & 11,3 & 49,7 & 16,5 & 21,0 & 12,8 & 68,6 & 12,7 & 48,9 \\
\hline V. & 17,5 & 50,6 & 20,1 & 27,4 & 14,0 & 150,8 & 17,3 & 78,9 \\
\hline VI. & 22,4 & 45,4 & 21,0 & 126,8 & 23,1 & 112,8 & 21,0 & 83,9 \\
\hline VII. & 23,4 & 64,0 & 22,1 & 131,6 & 22,6 & 57,4 & 22,7 & 62,1 \\
\hline VIII. & 23,7 & 30,0 & 23,6 & 36,3 & 23,4 & 82,2 & 22,2 & 65,1 \\
\hline IX. & 16,1 & 80,3 & 17,4 & 27,1 & 17,5 & 75,0 & 16,9 & 62,5 \\
\hline $\begin{array}{l}\text { IV.- IX. } \\
\text { Prosjek - Mean } \\
\text { Suma - Sum }\end{array}$ & 19,1 & 320,0 & 20,1 & 370,2 & 18,9 & 546,8 & 18,8 & 401,5 \\
\hline
\end{tabular}

*Temp. - Temp. - srednje mjesečne temperature zraka - mean monthly air temperatures

**Oborine - Precipit. - sume mjesečnih oborina - sum of monthly precipitations

Izvor: Državni hidrometeorološki zavod - Source: Croatian Meteorological and Hydrological Service

\section{REZULTATI I RASPRAVA}

\section{Urod zrna}

Rezultati AMMI analize varijance za urod zrna (Tablica 2) pokazali su statistički značajne razlike izme- đu genotipova $\mathrm{i}$ interakcija genotip $\mathrm{x}$ okolina $(\mathrm{P}<0,01)$ i okolina $(P<0,05)$. Najveći utjecaj na urod zrna imala je interakcija genotip $x$ okolina, kojoj je pripalo 41,72 $\%$ ukupne varijabilnosti. Genotipu je pripalo $20,75 \%$, a okolini $2,10 \%$ varijabilnosti. Suma kvadrata interakcije 
genotip x okolina bila je dvostruko veća u odnosu na genotip, što je pokazalo značajne razlike u reakciji genotipova u različitim okolinama. Slične rezultate su dobili Chauhan i sur. (1998.), Kaya i sur. (2002.) i
Tarakanovas i Ruzgas (2006.). Od IPCA osi, samo je IPCA1 bila visoko značajna $(P<0,01)$. Na IPCA1 se odnosilo 80,86, a na IPCA2 19,14\% interakcije genotip $\mathrm{x}$ okolina.

Tablica 2. AMMI analiza varijance za urod zrna (t/ha) 18 genotipova suncokreta u trima okolinama

Table 2. AMMI analysis of variance for grain yield (t/ha) of 18 sunflower genotypes across three environments

\begin{tabular}{|l|c|c|c|c|}
\hline Izvor - Source & $\mathrm{df}$ & SS & MS & SS (\%) \\
\hline Genotip - Genotype (G) & 17 & 25,885 & $1,523^{* *}$ & 20,75 \\
\hline Okolina - Environment (E) & 2 & 2,613 & $1,307^{*}$ & 2,10 \\
\hline GxE interakcija - Interaction (GEI) & 34 & 52,044 & $1,531^{* *}$ & 41,72 \\
\hline IPCA1 & 18 & 42,081 & $2,338^{* *}$ & 80,86 \\
\hline IPCA2 & 16 & 9,963 & 0,623 & 19,14 \\
\hline Pogreška - Error & 106 & 43,901 & 0,414 & \\
\hline Ukupno - Total & 161 & 124,732 & & \\
\hline
\end{tabular}

${ }^{*} \mathrm{i}$ ** značajnost na nivou $\mathrm{P}<0,05$ odnosno $\mathrm{P}<0,01-{ }^{*}$ and ${ }^{* *}$ significance at the $\mathrm{P}<0.05$ and $\mathrm{P}<0.01$, respectively; df - stupnjevi slobode - degrees of freedom; SS - suma kvadrata - sum of squares; MS - sredina kvadrata - mean square

Od analiziranih je okolina (Tablica 3) najveći prosječni urod zrna bio u 2018. godini (5,558 t/ha) zbog boljega rasporeda oborina u zimskim mjesecima i tijekom vegetacijskoga perioda, što je u skladu s istraživanjima Jukića i sur. (2019.), koji su također zbog boljega rasporeda oborina u 2018. godini dobili veće urode zrna i udjele ulja soje.

Poželjni hibridi suncokreta trebali bi imati visoke urode zrna u različitim okolinama, odnosno malu interakciju genotip $\mathrm{x}$ okolina. Na temelju mnogih istraživanja najrodniji genotipovi nisu bili i najstabilniji (Balalić i sur., 2007.; Naveed i sur., 2007.; Liović i sur., 2008.; Miklič i sur., 2009; Mustatea i sur., 2009.). Ovo je u skladu s našim istraživanjem, u kojem je najrodniji genotip 4 imao manju stabilnost u odnosu na druge genotipove, koji su imali nešto manji urod zrna.

Tablica 3. Prosječan urod zrna (t/ha) 18 hibrida suncokreta u trima okolinama

Table 3. Mean grain yield (t/ha) of 18 sunflower hybrids across three environments

\begin{tabular}{|c|c|c|c|c|c|c|c|c|}
\hline \multirow{2}{*}{$\begin{array}{l}\text { Genotip } \\
\text { Genotype (G) }\end{array}$} & \multicolumn{6}{|c|}{ Okolina - Environment (E) } & \multirow{2}{*}{$\begin{array}{l}\text { Prosjek } \\
\text { Mean }\end{array}$} & \multirow{2}{*}{$\begin{array}{l}\text { Ran } \\
\text { Ranl }\end{array}$} \\
\hline & 2017. & Rang - Rank & 2018. & Rang - Rank & 2019. & Rang - Rank & & \\
\hline 1 & 4,982 & 13 & 6,667 & 1 & 5,794 & 3 & 5,814 & 4 \\
\hline 2 & 5,441 & 10 & 5,821 & 7 & 5,042 & 11 & 5,434 & 9 \\
\hline 3 & 5,951 & 4 & 5,938 & 5 & 4,998 & 13 & 5,629 & 6 \\
\hline 4 & 6,647 & 2 & 5,711 & 9 & 5,536 & 5 & 5,965 & 1 \\
\hline 5 & 5,446 & 9 & 5,750 & 8 & 4,982 & 14 & 5,393 & 10 \\
\hline 6 & 5,304 & 11 & 5,841 & 6 & 5,449 & 9 & 5,532 & 8 \\
\hline 7 & 5,299 & 12 & 4,681 & 17 & 4,820 & 15 & 4,934 & 16 \\
\hline 8 & 5,659 & 7 & 3,720 & 18 & 3,917 & 18 & 4,432 & 18 \\
\hline 9 & 4,423 & 16 & 4,759 & 16 & 5,390 & 10 & 4,857 & 17 \\
\hline 10 & 6,411 & 3 & 5,470 & 13 & 5,979 & 2 & 5,953 & 2 \\
\hline 11 & 5,773 & 5 & 5,562 & 10 & 5,780 & 4 & 5,705 & 5 \\
\hline 12 & 4,839 & 14 & 6,221 & 3 & 5,013 & 12 & 5,358 & 12 \\
\hline 13 & 7,119 & 1 & 5,222 & 14 & 4,393 & 16 & 5,578 & 7 \\
\hline 14 & 4,679 & 15 & 5,544 & 12 & 5,461 & 8 & 5,228 & 14 \\
\hline 15 & 5,475 & 8 & 5,150 & 15 & 4,363 & 17 & 4,996 & 15 \\
\hline 16 & 4,080 & 18 & 5,555 & 11 & 6,500 & 1 & 5,379 & 11 \\
\hline 17 & 5,718 & 6 & 6,377 & 2 & 5,521 & 6 & 5,872 & 3 \\
\hline 18 & 4,232 & 17 & 6,059 & 4 & 5,515 & 7 & 5,269 & 13 \\
\hline \multirow[t]{2}{*}{$\begin{array}{l}\text { Prosjek } \\
\text { Mean }\end{array}$} & 5,416 & & 5,558 & & 5,247 & & 5,407 & \\
\hline & G & & $E$ & & $\mathrm{G} \times \mathrm{E}$ & & & \\
\hline LSD $5 \%$ & 0,601 & & 0,246 & & 1,042 & & & \\
\hline
\end{tabular}


Najveći prosječni urod zrna imao je genotip $4(5,965$ t/ha), a zatim 10 (5,953 t/ha), 17 (5,872 t/ha) i 1 (5,814 t/ha). U različitim okolinama isti su genotipovi imali različite rangove, odnosno različit poredak. Najrodniji je genotip 4 bio u 2017. po rangu drugi, 2018. deveti, a 2019. peti. Ovo je u skladu $s$ istraživanjima Chauhana i sur. (1998.), Ebdona i Gaucha (2002.), Raoa i sur. (2002.), Tarakanovasa i Ruzgasa (2006.) i Mohammadija i sur. (2007.), koji su također imali različit poredak istih genotipova u različitim okolinama.

Radi bolje preglednosti, rezultati AMMI analize prikazani su kao biplot koji prikazuje glavne aditivne učinke i interakcije sviju genotipova i okolina (Krizmanić i sur., 2008.; Silveira i sur., 2013.; Mirosavljević i sur., 2014.; Kendal i sur., 2019.; Tena i sur., 2019.). Prikazivanjem vrijednosti uroda zrna na osi x i IPCA1 na osi y grafikona, za 18 je genotipova i tri okoline formiran AMMI 1 biplot za urod zrna (Grafikon 1). Unutar biplota okomita se skala nalazi na prosječnoj vrijednosti uroda zrna $(5,407 \mathrm{t} / \mathrm{ha})$, a vodoravna je skala na nultoj vrijednosti IPCA1. Što je IPCA1 vrijednost nekoga genotipa bliže nuli, interakcija genotip $\mathrm{x}$ okolina je manja, pa je prema tome taj genotip stabilniji.

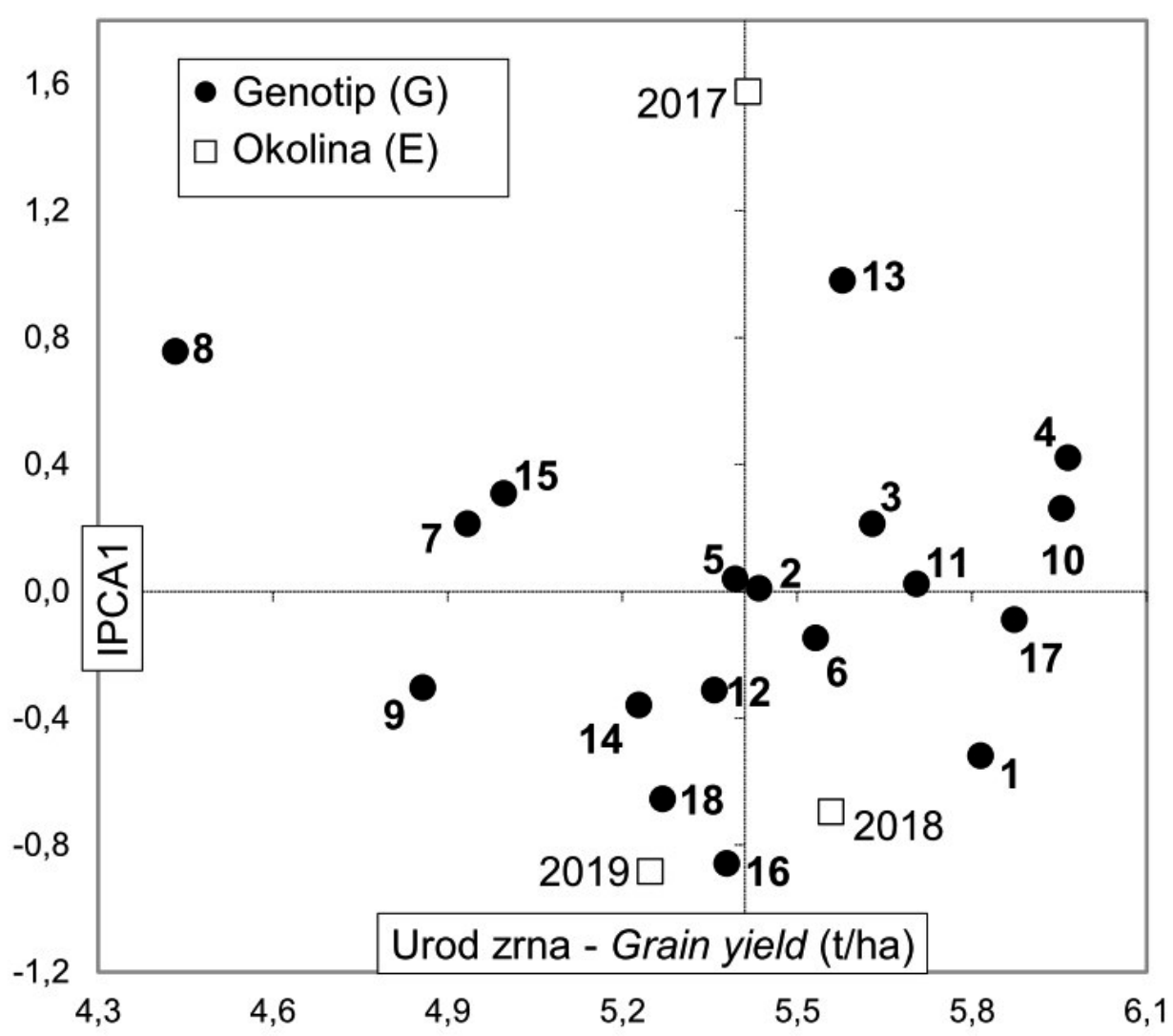

Grafikon 1. AMMI 1 biplot uroda zrna (t/ha) 18 hibrida suncokreta (G) u trima okolinama (E)

Graph 1. AMMI 1 biplot for grain yield (t/ha) of 18 sunflower hybrids (G) across three environments (E)

Na prikazanome se biplotu nalazi devet genotipova koji imaju veći urod zrna u odnosu na prosjek. Od tih genotipova, najveću apsolutnu vrijednost IPCA1 ima genotip 13, a zatim 1 i 4 . S obzirom na visinu uroda zrna i stabilnost, posebno se ističu genotipovi 4, 10, 17 i 11. Slične rezultate, u kojima su neki genotipovi imali visoki urod zrna i dobru stabilnost, dobili su Sauca i sur. (2010.), Kilic (2014.) i Pržulj i sur. (2015.). Od okolina su najveći urod zrna i najmanja interakcija genotip x okolina bili u 2018. godini.

\section{Sadržaj ulja}

U odnosu na urod zrna, sadržaj ulja pod manjim je utjecajem okolinskih uvjeta (Sudarić i sur., 2006.).
Sadržaj ulja je manji u uvjetima manjka oborina i visokih temperatura zraka tijekom cvatnje i zriobe (Mijić i sur., 2008.). Rezultati AMMI analize varijance sadržaja ulja (Tablica 4) pokazali su statistički značajne razlike $(P<0,01)$ između genotipova, okolina i interakcija genotip $x$ okolina. Na sadržaj ulja najveći je utjecaj imao genotip (52,82\% ukupne varijabilnosti), a zatim okolina $(23,02 \%)$ te interakcija genotip x okolina sa $17,27 \%$ varijabilnosti. Suma kvadrata genotipa bila je triput veća od interakcije genotip x okolina, što je pokazalo da različite okoline nisu bitno utjecale na sadržaj ulja istraživanih genotipova. Vrijednosti obje IPCA osi također su bile statistički značajne na nivou $P<0,01$. Os IPCA1 imala je 59,36, a IPCA2 40,64\% interakcije genotip x okolina. 
Tablica 4. AMMI analiza varijance za sadržaj ulja (\%) 18 genotipova suncokreta u trima okolinama

Table 4. AMMI analysis of variance for oil content (\%) of 18 sunflower genotypes across three environments

\begin{tabular}{|l|c|c|c|c|}
\hline Izvor - Source & $\mathrm{df}$ & $\mathrm{SS}$ & $\mathrm{MS}$ & SS (\%) \\
\hline Genotip - Genotype (G) & 17 & 964,053 & $56,709^{* *}$ & 52,82 \\
\hline Okolina - Environment (E) & 2 & 420,129 & $210,064^{* *}$ & 23,02 \\
\hline G x E interakcija - Interaction (GEI) & 34 & 315,153 & $9,269^{* *}$ & 17,27 \\
\hline IPCA1 & 18 & 187,088 & $10,394^{* *}$ & 59,36 \\
\hline IPCA2 & 16 & 128,065 & $8,004^{* *}$ & 40,64 \\
\hline Pogreška - Error & 106 & 124,837 & 1,178 & \\
\hline Ukupno - Total & 161 & 1825,329 & & \\
\hline
\end{tabular}

** značajnost na nivou $\mathrm{P}<0,01$ - ** significance at the $P<0.01$; df - stupnjevi slobode - degrees of freedom; SS - suma kvadrata - sum of squares; MS - sredina kvadrata - mean square

Od analiziranih okolina (Tablica 5), najveći je prosječni sadržaj ulja bio 2018 . godine $(50,75 \%)$, a najmanji 2017. $(47,01 \%)$. Najveći prosječni sadržaj ulja imao je genotip $8(54,54 \%)$, a zatim $9(51,59 \%), 13(51,53 \%), 17$ $(51,24 \%), 6(51,11 \%)$ i $16(50,84 \%)$.

Tablica 5. Prosječan sadržaj ulja (\%) 18 hibrida suncokreta u trima okolinama

Table 5. Mean oil content (\%) of 18 sunflower hybrids across three environments

\begin{tabular}{|c|c|c|c|c|c|c|c|c|}
\hline \multirow{2}{*}{$\begin{array}{l}\text { Genotip } \\
\text { Genotype (G) }\end{array}$} & \multicolumn{6}{|c|}{ Okolina - Environment (E) } & \multirow{2}{*}{$\begin{array}{l}\text { Prosjek } \\
\text { Mean }\end{array}$} & \multirow{2}{*}{$\begin{array}{l}\text { Rang } \\
\text { Rank }\end{array}$} \\
\hline & 2017. & Rang - Rank & 2018. & Rang - Rank & 2019. & Rang - Rank & & \\
\hline 1 & 47,23 & 9 & 50,15 & 12 & 47,25 & 16 & 48,21 & 13 \\
\hline 2 & 45,87 & 13 & 50,07 & 13 & 48,11 & 14 & 48,02 & 14 \\
\hline 3 & 43,55 & 16 & 47,59 & 17 & 44,69 & 18 & 45,28 & 17 \\
\hline 4 & 45,77 & 14 & 50,64 & 10 & 48,33 & 13 & 48,25 & 12 \\
\hline 5 & 43,94 & 15 & 42,06 & 18 & 48,67 & 12 & 44,89 & 18 \\
\hline 6 & 47,33 & 8 & 53,16 & 4 & 52,85 & 3 & 51,11 & 5 \\
\hline 7 & 47,79 & 7 & 51,40 & 9 & 50,02 & 10 & 49,74 & 9 \\
\hline 8 & 53,67 & 1 & 54,89 & 1 & 55,07 & 1 & 54,54 & 1 \\
\hline 9 & 51,26 & 2 & 51,66 & 7 & 51,85 & 6 & 51,59 & 2 \\
\hline 10 & 46,07 & 12 & 49,41 & 15 & 47,40 & 15 & 47,63 & 15 \\
\hline 11 & 46,16 & 11 & 49,73 & 14 & 49,65 & 11 & 48,51 & 11 \\
\hline 12 & 41,90 & 18 & 48,43 & 16 & 45,73 & 17 & 45,35 & 16 \\
\hline 13 & 50,73 & 3 & 52,13 & 6 & 51,74 & 7 & 51,53 & 3 \\
\hline 14 & 47,80 & 6 & 50,39 & 11 & 50,75 & 8 & 49,65 & 10 \\
\hline 15 & 46,27 & 10 & 52,45 & 5 & 52,08 & 5 & 50,27 & 7 \\
\hline 16 & 48,46 & 5 & 51,59 & 8 & 52,47 & 4 & 50,84 & 6 \\
\hline 17 & 49,44 & 4 & 54,13 & 2 & 50,13 & 9 & 51,24 & 4 \\
\hline 18 & 43,01 & 17 & 53,53 & 3 & 52,91 & 2 & 49,81 & 8 \\
\hline \multirow[t]{2}{*}{$\begin{array}{l}\text { Prosjek } \\
\text { Mean }\end{array}$} & 47,01 & & 50,75 & & 49,98 & & 49,25 & \\
\hline & G & & $\mathrm{E}$ & & $\mathrm{G} \times \mathrm{E}$ & & & \\
\hline LSD $5 \%$ & 1,01 & & 0,41 & & 1,76 & & & \\
\hline
\end{tabular}

Grafikon 2 prikazuje AMMI 1 biplot za sadržaj ulja. Okomita skala se nalazi na prosječnoj vrijednosti sadržaja ulja $(49,25 \%)$, a vodoravna na nultoj vrijednosti IPCA1. Na prikazanome biplotu nalazi se 10 genotipova koji imaju veći sadržaj ulja u odnosu na prosjek. Od tih genotipova, najveću apsolutnu vrijednost IPCA1 imao je genotip 18, a zatim 9,15 i 8 i 13 . S obzirom na visinu sadržaja ulja i stabilnost, posebno se ističu genotipovi 8 , $13,17,6$ i 16 


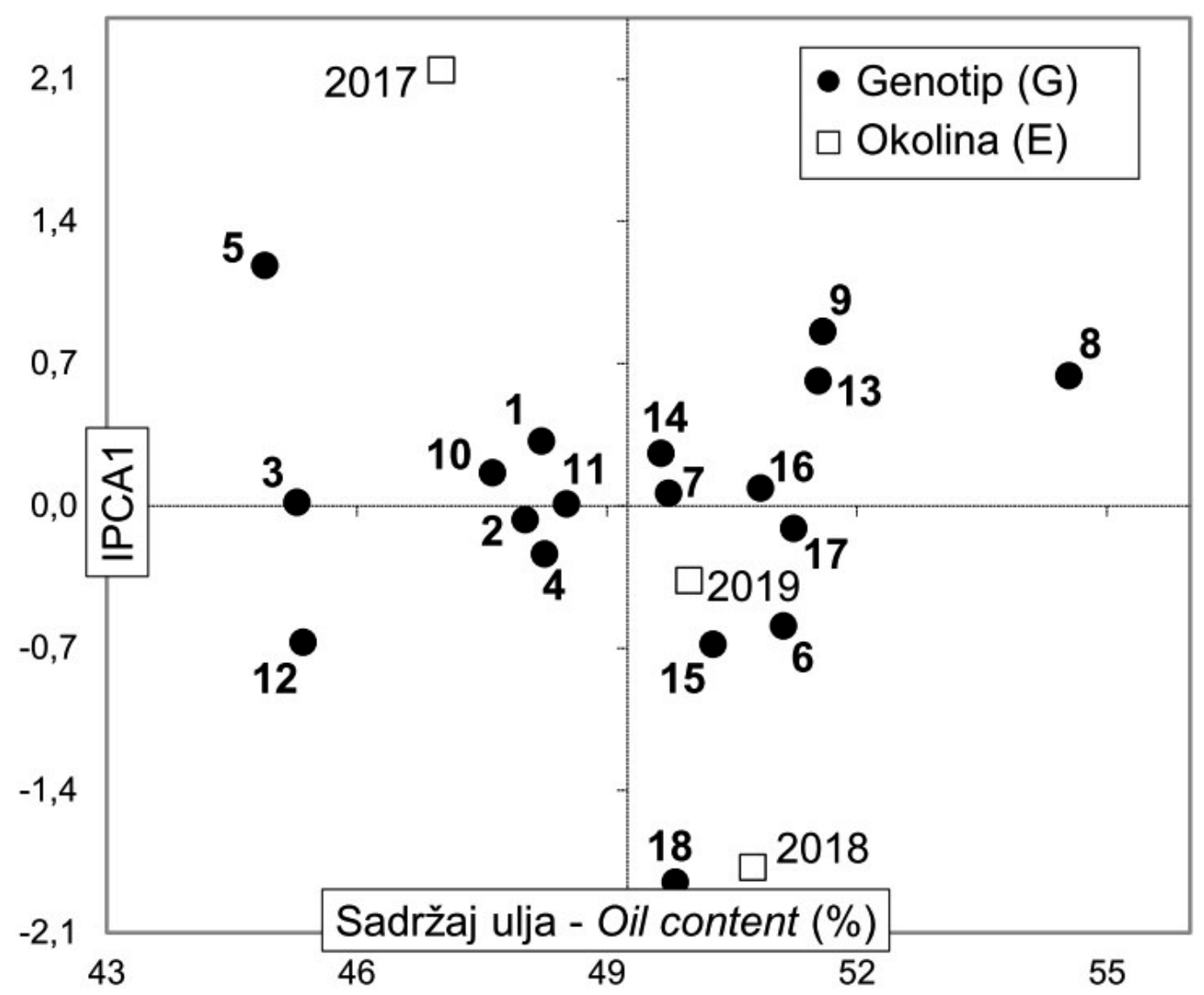

Grafikon 2. AMMI 1 biplot sadržaja ulja (\%) 18 hibrida suncokreta (G) u trima okolinama (E)

Graph 2. AMMI 1 biplot for oil content (\%) of 18 sunflower hybrids (G) across three environments (E)

Od okolina je najveću vrijednost sadržaja ulja, uz dosta veliku interakciju genotip x okolina, imala okolina 2018. Nešto manji sadržaj ulja imala je okolina 2019., ali i znatno manju interakciju genotip x okolina, odnosno znatno veću stabilnost u odnosu na ostale okoline.

\section{ZAKLJUČAK}

U trogodišnjim je istraživanjima (2017.-2019.) u poljskim pokusima s 18 hibrida suncokreta procijenjena interakcija genotip x okolina za urod zrna i sadržaj ulja AMMI analizom.

Na urod zrna najveći je utjecaj imala interakcija genotip x okolina $(41,72 \%)$, a zatim genotip $(20,75 \%)$ i okolina $(2,10 \%)$. S obzirom na visinu uroda zrna i stabilnost, posebno se ističu genotipovi 4, 10, 17 i 11. Najveći urod zrna i najmanja interakcija genotip $\mathrm{x}$ okolina bili su 2018. godine.

Na sadržaj ulja najveći je utjecaj imao genotip $(52,82 \%)$, a zatim okolina $(23,02 \%)$ te interakcija genotip $x$ okolina $(17,27 \%)$. S obzirom na visinu sadržaja ulja i stabilnost, posebno se ističu genotipovi 8, 13, 17, 6 i 16 . Najveći sadržaj ulja bio je u 2018. godini. Nešto manji sadržaj ulja je imala okolina 2019., ali znatno manju interakciju genotip x okolina, odnosno znatno veću stabilnost u odnosu na ostale okoline.
Provedena istraživanja ukazuju na postignuti genetski napredak u oplemenjivanju suncokreta Poljoprivrednoga instituta Osijek. Od novih hibridnih kombinacija posebno se ističe genotip 17, koji je imao visok i stabilan urod zrna i sadržaj ulja.

\section{LITERATURA}

1. Annicchiarico, P. (1997). Additive main effects and multiplicative interaction (AMMI) analysis of genotypelocation interaction in variety trials repeated over years. Theoretical and Applied Genetics, 94(8), 1072-1077. https://doi.org/10.1007/s001220050517

2. Balalić, I., Crnobarac, J., \& Dušanić, N. (2007). AMMI model in evaluation of planting date $\mathrm{x}$ hybrid interaction for sunflower grain yield. Proceedings of the $42^{\text {nd }}$ Croatian \& $2^{\text {nd }}$ International Symposium on Agriculture, Opatija, Hrvatska, 170.

3. Chauhan, Y. S., Wallace, D. H., Johansen, C., \& Singh, L. (1998). Genotype-by-environment interaction effect on yield and its physiological bases in short-duration pigeonpea. Field Crop Research, 59(2), 141-150. https://doi.org/10.1016/S0378-4290(98)00117-8

4. Ćirić, M., Ćurčić, Ž., Mirosavljević, M., MarjanovićJeromela, A., Jaćimović, G., Prodanović, S., \& Živanović, 
T. (2017). Assessment of sugar beet root yield by AMMI analysis. Genetika, 49(2), 663-675. https://doi.org/10.2298/GENSR1702663C

5. Ebdon, J. S., Petrovic, A. M., \& Zobel, R.W. (1998). Stability of Evapotranspiration Rates in Kentucky Bluegrass Cultivars across Low and High Evaporative Environments. Crop Science, 38(1), 135-142. https://doi. org/10.2135/cropsci1998.0011183X003800010023x

6. Ebdon, J. S., \& Gauch, H. G. (2002). Additive main effect and multiplicative interaction analysis of national turfgrass performance trials: I. Interpretation of genotype $x$ environment interaction. Crop Science, 42(2), 489-496. https://doi.org/10.2135/cropsci2002.4890

7. Eđed, A., Horvat, D., \& Petrović, S. (2008). Methods of Multivariate Statistics for Interpretation Genotype-Environment Interaction. Cereal Research Communications, 36(1), 259-262. https://doi.org/10.1556/CRC.36.2008.Suppl.1

8. FAOSTAT (2020). FAOSTAT Database. http://www.fao. org/faostat/en/\#data/QC

9. Galić Subašić, D., Jurišić, M., Sudarić, A., Josipović, M., \& Rapčan, I. (2017). Visina biljke i urod zrna soje u zavisnosti o godini, navodnjavanju i sorti. Poljoprivreda, 23(2), 19-24. https://doi.org/10.18047/poljo.23.2.3

10. Gauch, H. G. (1996). AMMI statistical analysis for increasing selection gains. Thirty second annual Illinois corn breeders' school, University of Illinois at UrbanaChampaign, USA, 1-12.

11. Gauch, H. G. (2006). Statistical analysis of yield trials by AMMI and GGE. Crop Science, 46(4), 1488-1500. https://doi.org/10.2135/cropsci2005.07-0193

12. Jocković, M., Ćirić, M., Jocić, S., Cvejić, S., Marinković, R., \& Miklič, V. (2012). Performance of NS sunflower hybrids in Romania. Selekcija $i$ semenarstvo, 18(1), 9-16.

13. Jug, D., Jug, I., Brozović, B., Vukadinović, V., Stipešević, B., \& Đurđević, B. (2018). The role of conservation agriculture in mitigation and adaptation to climate change. Poljoprivreda, 24(1), 35-44. https://doi.org/10.18047/poljo.24.1.5

14. Jukić, G., Mijić, Z., Šunjić, K., Varnica, I., \& Mijić, E. (2017). Utjecaj lokacije i godine na prinos ulja novijih hibrida suncokreta. Sjemenarstvo, 30(1-2), 5-10. https://doi.org/10.33128/s1.30.1-2.1

15. Jukić, G., Varnica, I., Dugalić, K., Rukavina, I., Guberac, V., \& Delić, I. (2019). Utjecaj genotipa, godine i lokacije na prinos, udio ulja i proteina u soji - Glycine max (L.) Merr. Poljoprivreda, 25(2), 3-10. https://doi.org/10.18047/poljo.25.2.1

16. Kaya, Y., Palta, C., \& Taner, S. (2002). Additive main effects and multiplicative interactions analysis of yield performances in bread wheat genotypes across environments. Turkish Journal of Agriculture and Forestry, 26(5), 275-279.

17. Kendal, E., Tekdal, S., \& Karaman, M. (2019). Proficiency of biplot methods (AMMI and GGE) in the appraisal of triticale genotypes in multiple environments. Applied Ecology and Environmental Research, 17(3), 5995-6007. http://dx.doi.org/10.15666/aeer/1703_59956007
18. Kilic, H. (2014). Additive Main Effects and Multiplicative Interactions (AMMI) Analysis of Grain Yield in Barley Genotypes Across Environments. Journal of Agricultural Sciences, 20(4), 337-344. https://doi.org/10.15832/tbd.44431

19. Krizmanić, M., Mijić, A., Cupić, T., Duvnjak, V., \& Puškadija, Z. (2008). Biplot analysis of sunflower plant height on different soils and precipitations. Cereal Research Communications, 36(Suppl.), 1331-1334. https://doi.org/10.1556/crc.36.2008.suppl.2

20. Li, W., Yan, Z. H., Wei, Y. M., Lan, X. J., \& Zheng, Y. L. (2006). Evaluation of genotype $x$ environment interactions in Chinese spring wheat by the AMMI model, correlation and path analysis. Journal of Agronomy and Crop Science, 192(3), 221-227.

https://doi.org/10.1111/j.1439-037X.2006.00200.x

21. Liović, I., Josipović, M., Šimić, D., Krizmanić, G., \& Mijić, A. (2008). Marketable tuber yield stability in potato. Cereal Research Communications, 36(Suppl.), 87-90. https://doi.org/10.1556/crc.36.2008.suppl.1

22. Liović, I., Mijić, A., Markulj Kulundžić, A., Duvnjak, T., \& Gadžo, D. (2017). Utjecaj vremenskih uvjeta na urod zrna, sadržaj ulja i urod ulja novih OS hibrida suncokreta. Poljoprivreda, 23(1), 34-39.

http://dx.doi.org/10.18047/poljo.23.1.6

23. Mijić, A., Krizmanić, M., Liović, I., Marić, S., \& Duvnjak, T. (2008). Influence of different soil types and rainfall conditions on oil content in sunflower. Cereal Research Communications, 36(Suppl.), 1327-1330. https://doi.org/10.1556/crc.36.2008.suppl.2

24. Mijić, A., Liović, I., Zdunić, Z., Marić, S., Marjanović Jeromela, A., \& Jankulovska, M. (2009). Quantitative analysis of oil yield and its components in sunflower (Helianthus annuus L.). Romanian Agricultural Research, 26, 41-46.

25. Miklič, V., Balalić, I., Jocić, S., Marinković, R., Hladni, N., Gvozdenović, S., \& Stojšin, V. (2009). Produktivnost NS hibrida suncokreta u multilokacijskim ogledima i preporuka sortimenta za setvu u 2009. godini. Zbornik radova Instituta za ratarstvo i povrtarstvo, 46(2), 293310.

26. Mirosavljević, M., Pržulj, N., \& Čanak, P. (2014). Analysis of new experimental barley genotype performance for grain yield using AMMI biplot. Selekcija i semenarstvo, 20(1), 27-36. https://doi.org/10.5937/SelSem1401027M

27. Mohammadi, R., Armion, M., Shabani, A., \& Daryaei, A. (2007). Identification of stability and adaptability in advanced durum genotypes using AMMI analysis. Asian Journal of Plant Sciences, 6(8), 1261-1268. http://dx.doi.org/10.3923/ajps.2007.1261.1268

28. Mustatea, P., Saulescu, N. N., Ittu, G., Paunescu, G., Voinea, L., Stere, I., Mirlogeanu, S., Constantinescu, E., \& Nastase, D. (2009). Grain yield and yield stability of winter wheat cultivars in contrasting weather conditions. Romanian Agricultural Research, 26, 1-8.

29. Naveed, M., Nadeem, M., \& Islam, N. (2007). AMMI analysis of some upland cotton genotypes for yield stability in different milieus. World Journal of Agricultural Sciences, 3(1), 39-44. 
30. Pržulj, N., Mirosavljević, M., Čanak, P., Zorić, M., \& Boćanski, J. (2015). Evaluation of Spring Barley Performance by Biplot Analysis. Cereal Research Communications, 43(4), 692-703.

https://doi.org/10.1556/0806.43.2015.018

31. Rao, M. S. S., Mullinix, B. G., Rangappa, M., Cebert, E., Bhagsari, A. S., Sapra, V. T., Joshi, J. M., \& Dadson, R.B. (2002). Genotype $\times$ environment interactions and yield stability of food-grade soybean genotypes. Agronomy Journal, 94(1), 72-80.

https://doi.org/10.2134/agronj2002.7200

32. SAS Institute Inc. (2003). SAS for Windows (r) 9.1. Cary, NC, USA.

33. Sauca, F., Petcu, E., Stanciu, D., \& Stanciu, M. (2010). Preliminary identification of Romanian sunflower hybrids suitable for organic agricultural system. Romanian Agricultural Research, 27, 43-46.

34. Silveira, L. C. I., Kist, V., Paula, T. O. M., Barbosa, M. H. P., Peternelli, L. A., \& Daros, E. (2013). AMMI analysis to evaluate the adaptability and phenotypic stability of sugarcane genotypes. Scientia Agricola, 70(1), 27-32. http://dx.doi.org/10.1590/S0103-90162013000100005
35. Sudarić, A., Šimić, D., \& Vratarić, M. (2006). Characterization of genotype by environment interactions in soybean breeding programmes of southeast Europe. Plant Breeding, 125(2), 191-194. https://doi.org/10.1111/j.1439-0523.2006.01185.x

36. Tarakanovas, P., \& Ruzgas, V. (2006). Additive main effect and multiplicative interaction analysis of grain yield of wheat varieties in Lithuania. Agronomy Research, 4(1), 91-98.

37. Tena, E., Goshu, F., Mohamad, H., Tesfa, M., Tesfaye, D., \& Seife, A. (2019). Genotype x environment interaction by AMMI and GGE-biplot analysis for sugar yield in three crop cycles of sugarcane (Saccharum officinirum L.) clones in Ethiopia. Cogent Food \& Agriculture, 5(1), 1651925 .

38. Zobel, R. W., Wright, M. J., \& Gauch, H. G. (1988). Statistical Analysis of a Yield Trial. Agronomy Journal, 80(3), 388-393. https://doi.org/10.2134/agronj1988.000 21962008000030002x

39. Yan, W., \& Tinker, N. A. (2005). An integrated biplot analysis system for displaying, interpreting, and exploring genotype $x$ environment interaction. Crop Science, 45(3), 1004-1016.

https://doi.org/10.2135/cropsci2004.0076

\section{STABILITY ESTIMATION OF THE GRAIN YIELD AND OIL CONTENT OF SUNFLOWER HYBRIDS BY AMIMI ANALYSIS}

\section{SUMMARY}

During three growing seasons (2017-19), the field trials implying 18 sunflower hybrids were set up on the areas of the Agricultural Institute Osijek. The research objective was to evaluate a genotype $x$ environment interaction pertaining to a grain yield ( $t / h a)$ and oil content (\%). A genotype $x$ environment interaction for both traits was evaluated by the AMMI (Additive Main Effects and Multiplicative Interaction) analysis. Statistically significant differences were established between the genotypes, environments, and the genotype x environment interactions concerning a grain yield, while the relatively largest proportion of sum of squares was manifested by a genotype $x$ environment interaction (41.72\%), followed by the genotype (20.75\%) and the environment (2.10\%). Regarding a grain yield level and stability, the genotypes 4, 10, 17 and 11 were particularly prominent. Concerning the environments, the highest grain yield and the lowest genotype $x$ environment interaction were in 2018. Statistically significant differences between the genotypes, environments, and genotype $x$ environment interactions were also detected concerning the oil content, while the largest proportion of sum of squares was manifested by the genotype (52.82\%), followed by the environment (23.02\%) and a genotype $x$ environment interaction (17.27\%). Regarding an oil content level and stability, the genotypes 8, 13, 17, 6 and 16 stood out particularly. Concerning the environments, the 2019 one had a slightly lower oil content but a considerably less genotype $x$ environment interaction and, respectively, a higher stability in relation to other environments.

Keywords: sunflower, grain yield, oil content, AMMI analysis, genotype x environment interaction

(Primljeno 6. lipnja 2020.; prihvaćeno 5. ožujka 2021. - Received on June 6, 2020; accepted on March 5, 2021) 